\title{
Web GIS Solution for Monitoring the Forest-Cover in the Mekong Delta, Vietnam
}

\author{
Le Van Trung1,2*, Dao Minh Tam ${ }^{1}$ \\ ${ }^{1}$ Geomatics Center, Vietnam National University, Ho Chi Minh City, Vietnam \\ ${ }^{2}$ Ho Chi Minh City University of Technology, Vietnam National University, Ho Chi Minh City, Vietnam \\ Email: *lvtrungbk@gmail.com
}

How to cite this paper: Van Trung, L. and Tam, D.M. (2018) Web GIS Solution for Monitoring the Forest-Cover in the Mekong Delta, Vietnam. Journal of Geographic Information System, 10, 491-502. https://doi.org/10.4236/jgis.2018.105026

Received: August 9, 2018

Accepted: September 11, 2018

Published: September 14, 2018

Copyright ( 92018 by authors and Scientific Research Publishing Inc. This work is licensed under the Creative Commons Attribution International License (CC BY 4.0).

http://creativecommons.org/licenses/by/4.0/

(c) (i) Open Access

\begin{abstract}
In recent years, Web GIS has been widely applied in mapping and sharing spatial data. This paper introduces a Web GIS solution has been applied to establishing "The Mekong Delta Geographic Information Systems-MGIS". The development and implementation of a web-based MGIS are a suitable technology for monitoring and managing the natural resources and environment that aims to achieve sustainable development in the Mekong Delta region. The proposed solution shows that Web GIS can be applied effective to for integrating and sharing data among administration agencies in order to provide fully integrated information of updated on the status of land cover changes and analyzing the trend of forest-cover changes in this region. Results of this study illustrate the MGIS's applications in sharing of regional data that allows multiple users to use tools for displaying spatial distribution of forest-cover in the period from the year 1990 to 2015 and analyzing the trend of changes.
\end{abstract}

\section{Keywords}

Geographic Information System, Web-Based GIS, Forest-Cover Change, MGIS, Mekong Delta

\section{Introduction}

Geographic Information Systems (GIS) are a powerful set of tools for collecting, storing, analyzing, integrating and sharing spatial data among administration agencies. Adnan et al. (2010) have demonstrated that an important part of every web-based GIS application is its mapping or visualization technology, which makes it possible to show data in the form of maps [1]. Odil Kurbanov (2015) has discussed how to provide a way to allow the staff of law enforcement agen- 
cies to easily manage the data using open source web GIS platform enabling users to access, visualize and interact with the data online within a web browser [2]. However, these have not been the case for the project MGIS “The Mekong Delta Geographic Information Systems" which is funded by the Ministry of Science and Technology of Vietnam. The project is established to rely on integrating and sharing data among administration agencies of the 12 provinces and a city in order to meet the requirements of supporting local leadership in decisions maker in planning and sustainable development in the Mekong Delta region. At present, the People Committee of 12 provinces and a city in this region are unable to undertake comprehensive and coordinated land use planning based on the state of the environment and natural resources and future development needs. Many agencies have deployed GIS as a tool to modernize their management and to strengthen their administrative machinery. Some provinces have been undertaking projects on specific purposes, related to the applications on the integrity of remote sensing and GIS technologies (such as land use management, forest resource analysis). Due to the spontaneity of agencies in deploying GIS technology, some problems emerge: duplication in data collection effort among organizations, different geographic data themes for an area, and difficulties in sharing information among organizations because of both mechanisms of management and technology.

Therefore, MGIS database management system must be established based on the technical conditions of each province so that ensures the efficiency of investment in providing data from a variety of sources. The choice of an appropriate database management model in the development a web-based GIS plays an important role in sharing and updating data synchronization. The Web GIS applications must be created by the user interfaces that provide online tools that allow specified users to display in the form of thematic maps, to edit data and to create solutions for supporting local leadership in decisions maker for planning and sustainable development in the Mekong Delta region. In addition, all end users can get the Web GIS applications based on integration of multiple different databases and agencies and flow logic to arrive at the desired result with minimal time and without expert GIS knowledge.

This paper introduces the development and implementation of a web-based GIS that can be used as a tool for planning socio-economic development, natural resources and environmental management at different levels in the region. The proposed method shows that Web GIS can be applied effective to for integrating and sharing data among administration agencies in order to provide fully integrated information of updated on the status of land cover changes and analyzing the trend of forest-cover changes in Mekong Delta region.

\section{Study Area}

Mekong Delta has been selected as the research area as it is identified as significantly vulnerable to climate change. Mekong Delta is a region having very high risk of inundation. If sea-level rises $100 \mathrm{~cm}$, approximately 38.9\% of Mekong 
River Delta would be at risk of flooding [3]. The Mekong Delta region with total land area about $39,000 \mathrm{~km}^{2}$ comprises a city of Can Tho and 12 provinces of Tien Giang, Long An, Ben Tre, Vinh Long, An Giang, Dong Thap, Tra Vinh, Hau Giang, Soc Trang, Kien Giang, Bac Lieu and Ca Mau.

The main MGIS project goal is to design and implement comprehensive information system tools which support regional and provincial government agencies in the Mekong Delta in their planning processes to develop the region and adapt to climate change in the context of sustainable development. MGIS has been divided into two phases in Figure 1. In the first project phase (2015-2017) a prototypical Geographic Information System was developed and implemented and a centralized database was created for sharing and updating data synchronization based on Web GIS applications: 1) to establish an suitable model to provide information for planning and development of regional socio-economic, 2) to build an appropriate database management system in sharing and updating data synchronization, in order to create Web GIS applications and 3) to provide general solutions for Can Tho, Vinh Long and An Giang in building GIS database in order to develop MGIS to easily connect databases with the remaining 10 provinces. The MGIS Information System is the central access point for all MGIS data products integrated from by project disciplines like hydrology, geochemistry, socio-economics, geography, and earth observation and generated by the project in the provinces of Vinh Long, An Giang and Can Tho city. If results of the first phase are checked to meets all demands of the users, it will be extended in the second phase (2018-2020) for generating and integrating data of the remaining provinces.

\section{Methodology}

\subsection{Database Management System of MGIS}

MGIS database management system must be established so that can provide exact data when is required from a variety of sources. Base map (topographic maps), thematic maps (cadastral maps, land use maps) and remote sensing data are available can be used in different situations. A mixed-scale approach involving the integration of data was applied. All data were change in data format and projection (Datum: VN2000) for integrating and sharing data in response to different user requests.

Base map of Mekong Delta region has been generated from topographic map at 1:250,000 scale includes 7 basic layers: Mathematical basis, Boundary, Elevation, Transportation, Hydrology, Urban areas, Vegetation as shown in Figure 2. It serves as general base information to made thematic map at regional level. Topographic map of each province at 1:50,000 scale is also used to generate base map at the provincial level that have been shared as geospatial data services. This solution allows multiple users to access the same data at the same time via an intranet and/or the internet in a safe and high secure manner and avoids duplication of work, inconsistencies of data, delays, confusion and waste of resources. 


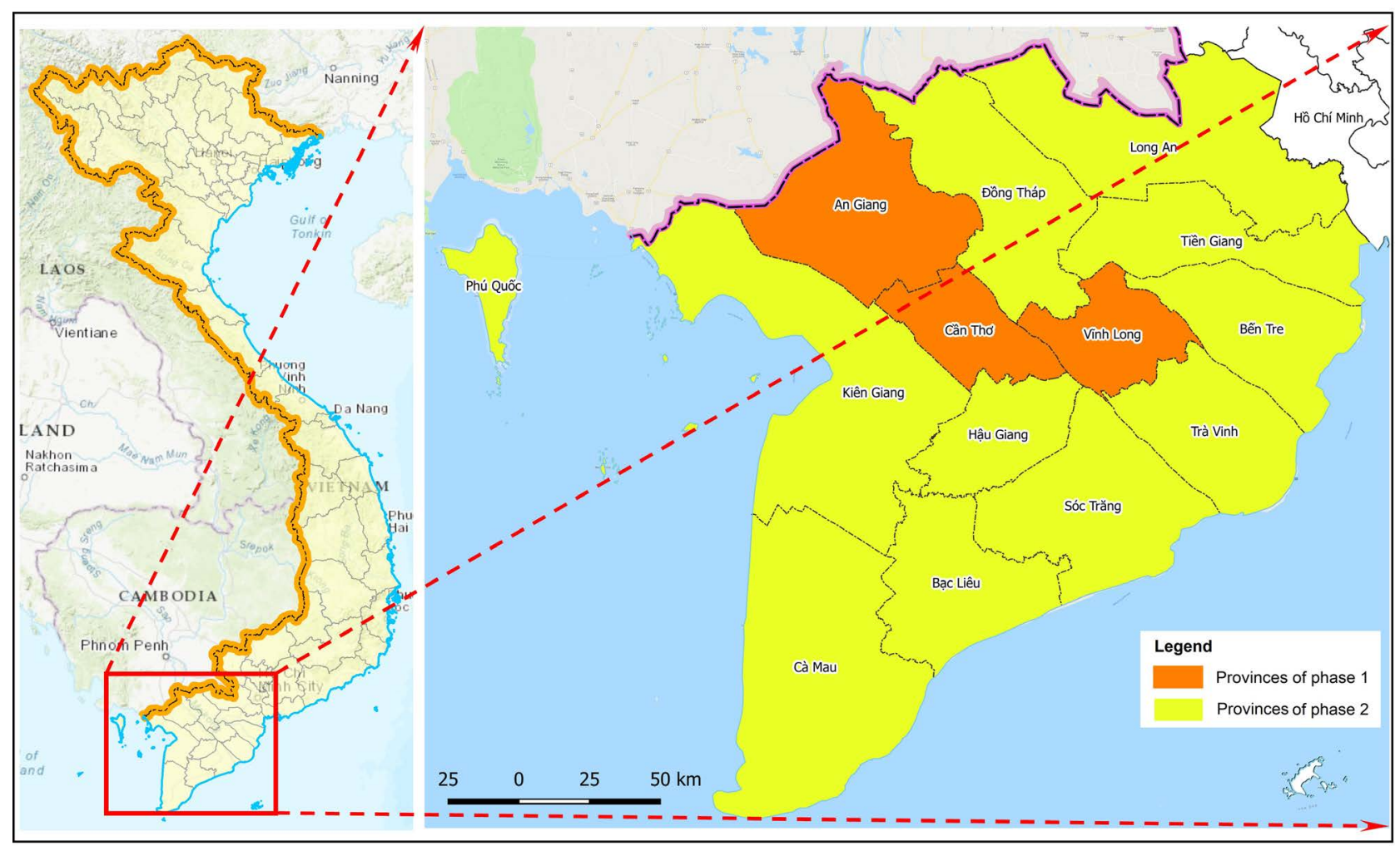

Figure 1. Location of the Can Tho city, Vinh Long and An Giang province in Mekong Delta region.

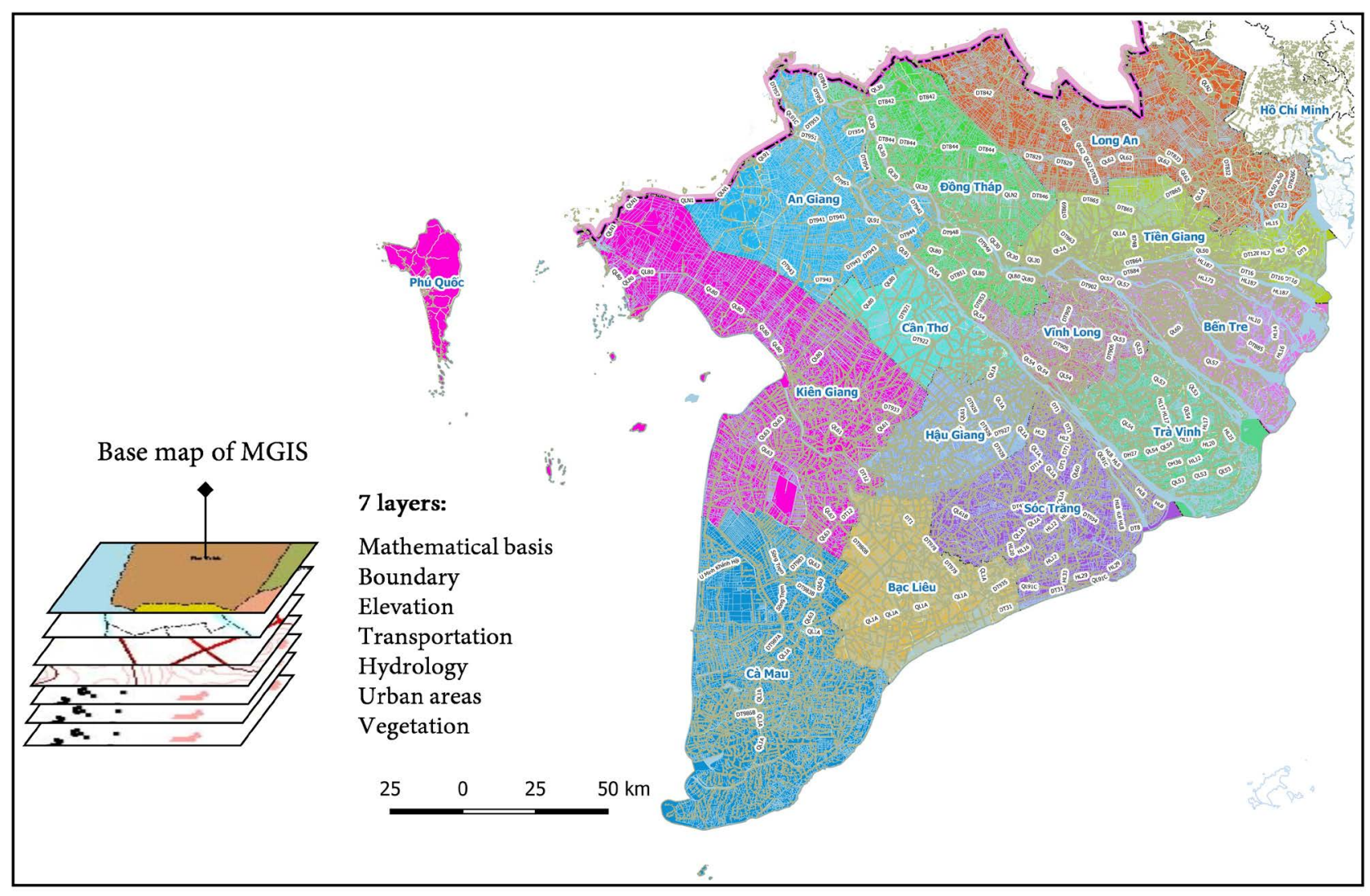

Figure 2. Topographic map at 1:250,000 scale of Mekong Delta region. 
Thematic maps have been established from the previous projects such as vegetation, transportation and hydrology networks, land use change, river bank change, as well as remote sensing data includes all image of the fact of floods and salinity intrusion. The thematic database is established to provide data layers that create useful information for supporting local leadership in decisions maker in planning and sustainable development in the Mekong Delta region.

The database standard of MGIS is an important key for sharing among 12 provinces and a city in Mekong Delta region. Because base maps can be used to develop GIS applications by administration agencies and also allows multiple users and integrate information as management requirements at the macro level in order to display in the form of thematic maps based on Web GIS applications. Therefore, the National Geospatial Standards of Vietnam have been applied for building MGIS to serve operation and management that aims to avoid wasteful overlapping investment and to create GIS database based on the technical conditions of each province to serve for sustainable development of this region. MGIS's geospatial data consist of base maps and thematic maps of different scales in Figure 3: for regional level at 1:250,000; for provincial level 1:50,000; for district 1:10,000; and for commune 1:500 or 1:2000.

\subsection{Choosing the Appropriate Web GIS Solution for Serving MGIS}

MGIS database management system must be established so that can provide exact data when is required from a variety of sources. The Web GIS applications will be created mainly for sharing and updating data synchronization and providing online tools that allow specified users to display in the form of thematic maps, to edit data and to create solutions for mapping and monitoring the natural resources changes in order to support management. The MGIS system architecture follows a client-server architecture in Figure 4. The MGIS applications was designed and developed based on the current open source software applications in Table 1 in order to reduce installation costs and permit further adaptations to meet necessary project requirements. The .NET Core and ASP.NET Core framework were used for server side programming, that are fully open source and available on Windows, Mac, and Linux, and can be used in device, cloud, and embedded/IoT scenarios [4]. In the MGIS information system, all data were stored in a PostgreSQL database. PostgreSQL is an open source object-relational database management system that can store geospatial data with Post GIS geospatial extensions [5]. Map services were created using GeoServer, which is an open source platform for publishing geospatial data and interactive mapping applications [6]. The client web-based geographic application as the user interface, was developed using Open Layers APIs library which was originally based on the Prototype JavaScript Framework [7].

The MGIS information system implements a three-tier architecture as shown in Figure 5 to serve different user requests indicates the response time of the database management system of MGIS for natural resources management. The 
user interface is on the 1st tier that data and maps can be presented on a web browser (website: https://mgis.vn) without the need for any additional software. All web-based GIS applications lie on the 2nd tier implements the functionality of MGIS with an application framework that can be used to build other applications such as user management, menu systems. MGIS database lies on the 3rd tier and is managed by PostgreSQL software that users can download or upload data to contribute content of MGIS database. GeoServer is used for dealing with spatial and attribute data available inside of MGIS database and provides service in connecting to database of other provinces that content can be requested to open other layers outside of MGIS through Web Feature Service (WFS) standard, or the Web Map Service (WMS) protocols.

Table 1. Open source software applications used.

\begin{tabular}{ccc}
\hline Software Application & Version & Function \\
\hline PostgreSQL 9.5 & 10.1 & Object relational database \\
PostGIS & 2.4 .1 & $\begin{array}{c}\text { Spatial database extension } \\
\text { GeoServer }\end{array}$ \\
2.12 .1 & 4.3 .2 & Share geospatial data \\
OpenLayers APIs libraries & 2.1 & Development of geographic user interface \\
NET Core/ASP.NET Core & & $\begin{array}{c}\text { Framework for building Internet-connected } \\
\text { applications }\end{array}$ \\
\hline
\end{tabular}

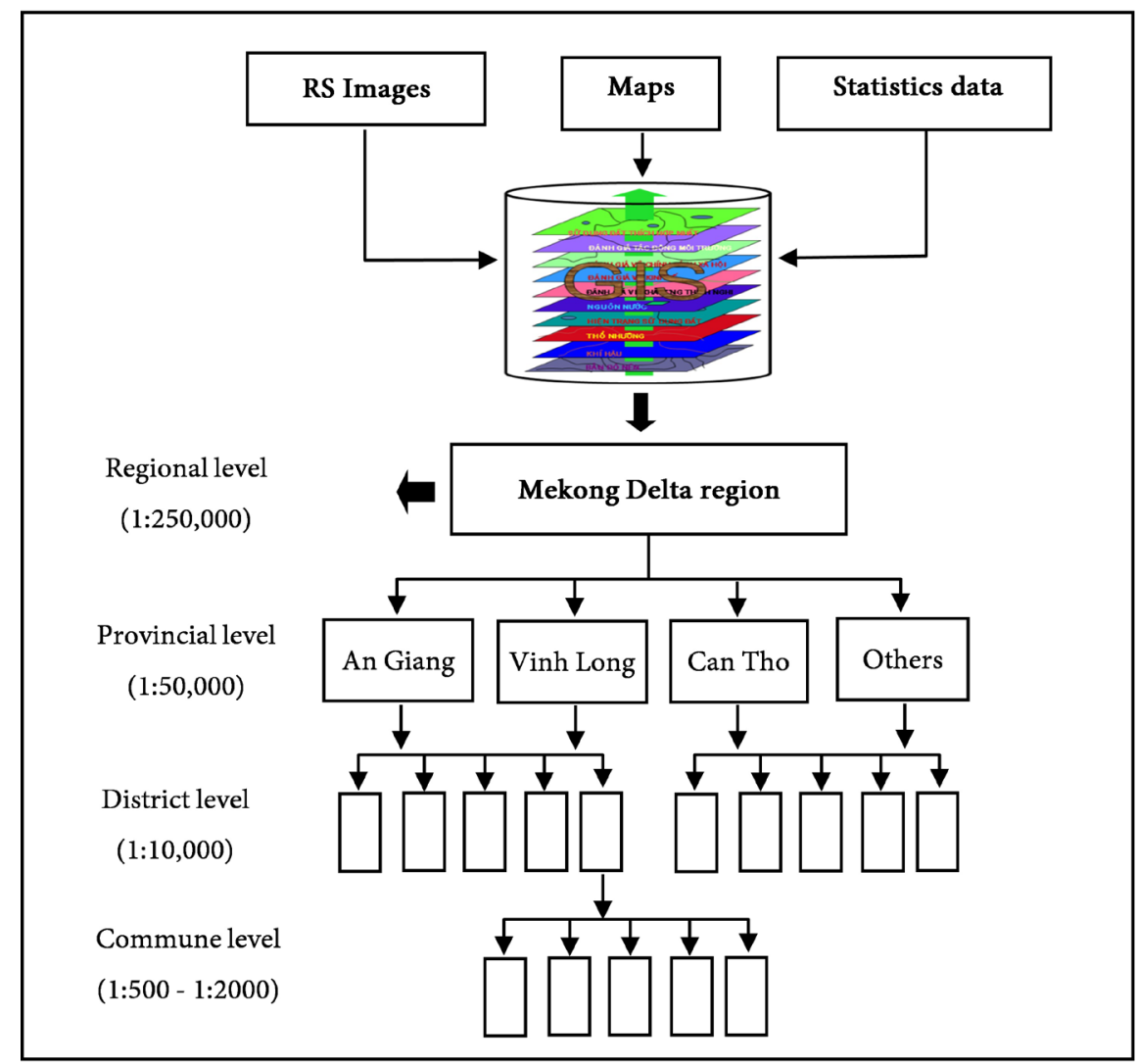

Figure 3. The different scales in database management of MGIS. 


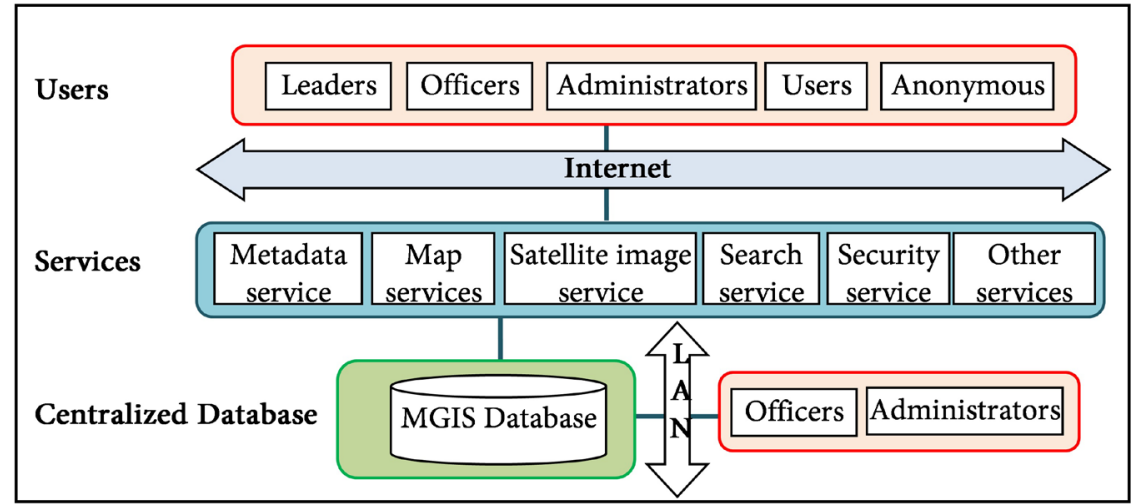

Figure 4. The MGIS information system architecture.

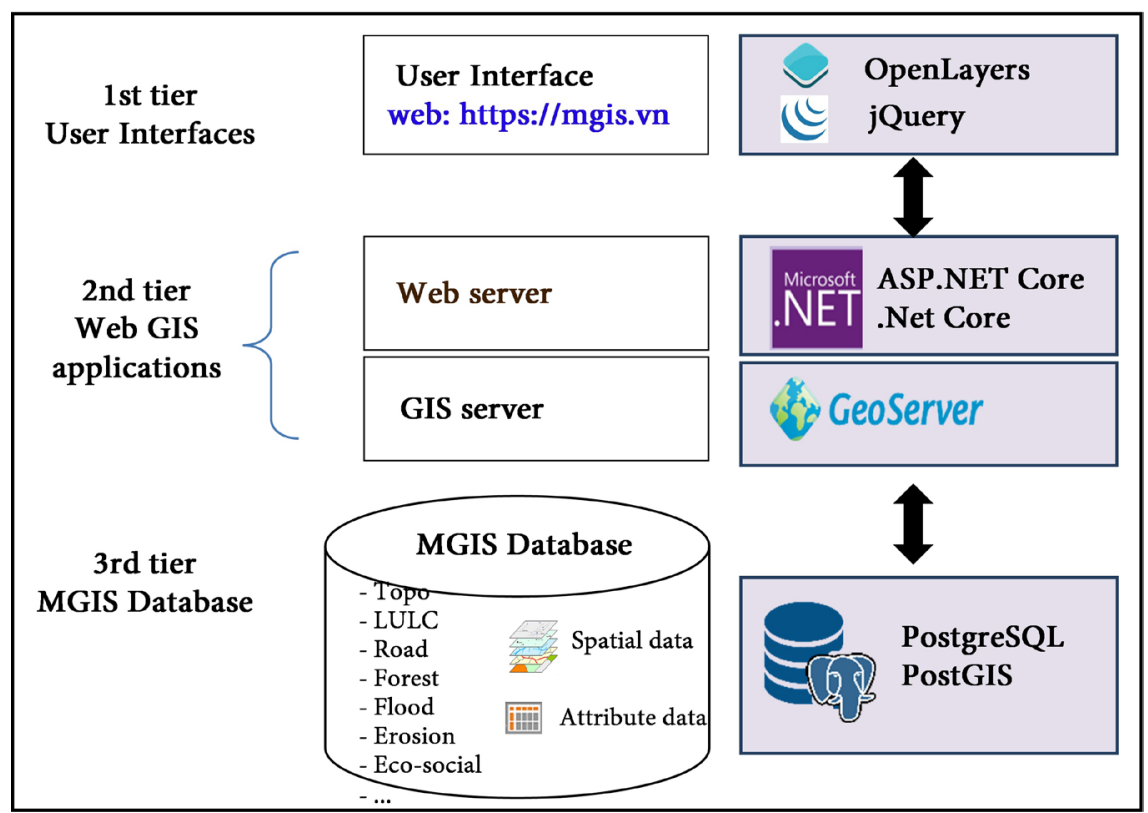

Figure 5. Three tiers architecture of MGIS Information System.

\section{Results and discussion}

\subsection{Web GIS for Sharing Data of MGIS}

The MGIS information system hosted on the https://mgis.vn in Figure 6. Database of the MGIS includes various data sources and satellite images to support for monitoring of changes in natural resources, environmental and socio-economic. Sharing of regional data allows multiple users to use the same data at the same time via the internet in a safe and can bring more value on understanding the regional level situation. Web GIS application is a good opportunity for 12 provinces and a city to share data for managing and supporting the sustainable development in Mekong Delta region.

\subsection{Web GIS for Investigating the Spatial Distribution of Forest-Cover Change}

Thematic data group of MGIS includes forest-cover thematic maps of Mekong 
Delta in the period from the year 1990 to 2015 in Figure 7 and the total area of forest-cover of 12 provinces and a city show in Table 2.

The online mapping application was developed that is mainly composed of data handling tools for analyzing the trend and displaying spatial distribution of forest-cover change. The result in Table 3 shows that the total area of the forest-cover has decreased with the average cover rate from $10.4 \%$ of the natural area at the year 1990 to $4.1 \%$ of the area in 2015. Almost the forest-cover area of Hau Giang province has been converted to non-forest land cover.

Web GIS demonstrated an efficient solution for visualization of a very large amount of thematic data of MGIS that show the area of the forest-cover has decreased with the average cover rate.

The result in Table 2 also shows that in 2 provinces of An Giang, Vinh Long, and Can Tho city of the project's phase 1, the highest loss of forest cover was from 1990 to 2015 with a significant decline of 11,713 ha forest loss in An Giang. The Figure 8 shows the spatial distribution of forest cover for the year 2015 in An Giang. The administration agency of An Giang can visualize and interact with forest-cover thematic map and find out due to causes of fire damage or human impacts.

Table 2. The total area of forest-cover of 12 provinces and a city in Mekong Delta region.

\begin{tabular}{ccccc}
\hline No. & $\begin{array}{c}\text { Name of } \\
\text { province }\end{array}$ & $\begin{array}{c}\text { Area (1990) } \\
\text { (ha) }\end{array}$ & $\begin{array}{c}\text { Area (2005) } \\
\text { (ha) }\end{array}$ & $\begin{array}{c}\text { Area (2015) } \\
\text { (ha) }\end{array}$ \\
\hline 1 & An Giang & 18,922 & 17,581 & 7209 \\
2 & Bac Lieu & 2636 & 2815 & 875 \\
3 & Ben Tre & 9627 & 5687 & 3260 \\
4 & Ca Mau & 130,102 & 96,038 & 72,260 \\
5 & Can Tho & 0 & 0 & 0 \\
6 & Dong Thap & 24,116 & 9594 & 10,661 \\
7 & Hau Giang & 2841 & 0 & 0 \\
8 & Kien Giang & 73,860 & 78,796 & 33,735 \\
9 & Long An & 89,594 & 56,334 & 22,419 \\
10 & Soc Trang & 11,162 & 8251 & 7542 \\
11 & Tien Giang & 27,949 & 15,097 & 2182 \\
12 & Tra Vinh & 17,599 & 2128 & 2305 \\
13 & Vinh Long & 0 & 0 & 0 \\
\hline
\end{tabular}

Table 3. The trend of forest-cover change in Mekong Delta region from 1990 to 2015.

\begin{tabular}{ccc}
\hline Year & Area (ha) & Forest-cover rate (\%) \\
\hline 1990 & 409,428 & 10.4 \\
2005 & 296,417 & 7.5 \\
2015 & 162,752 & 4.1 \\
\hline
\end{tabular}




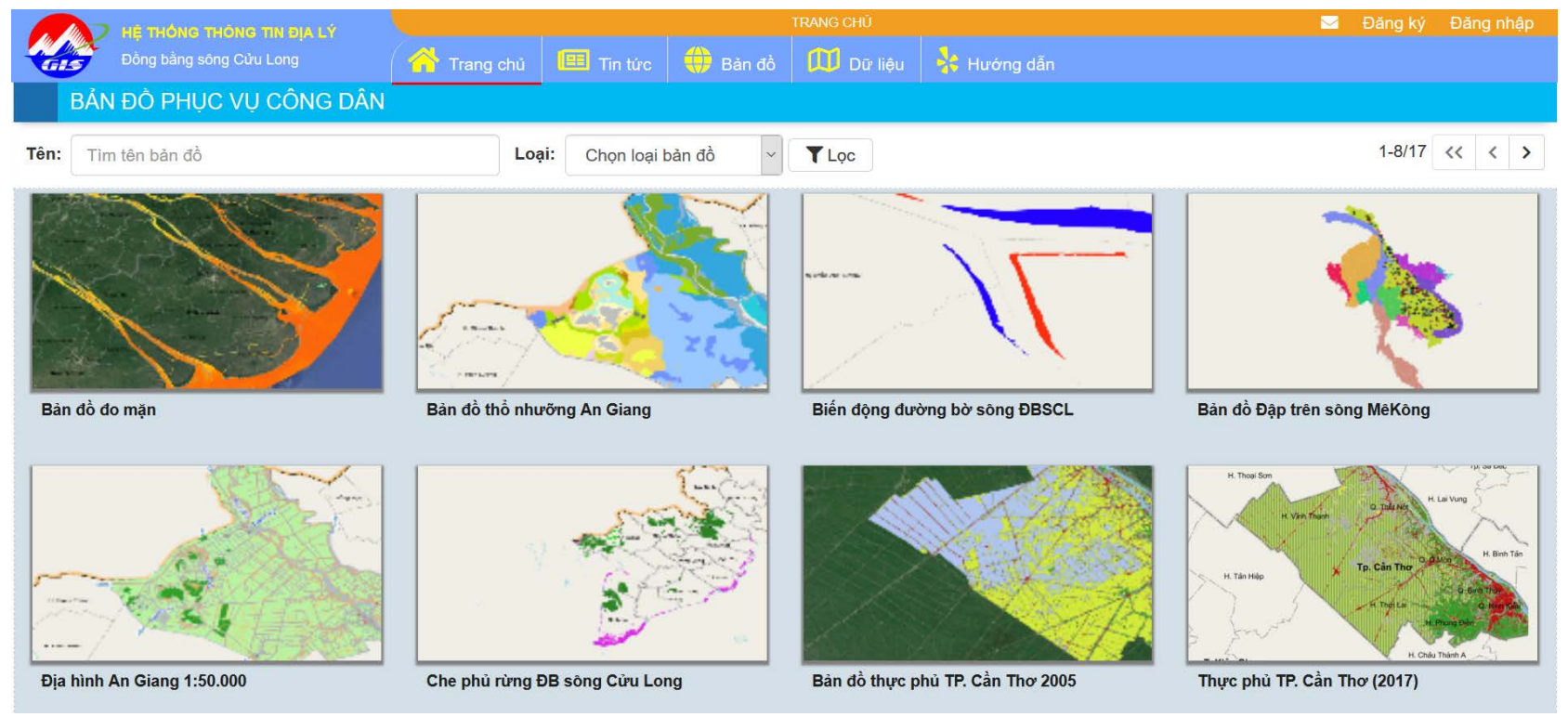

Figure 6. Home page of MGIS at https://mgis.vn/.

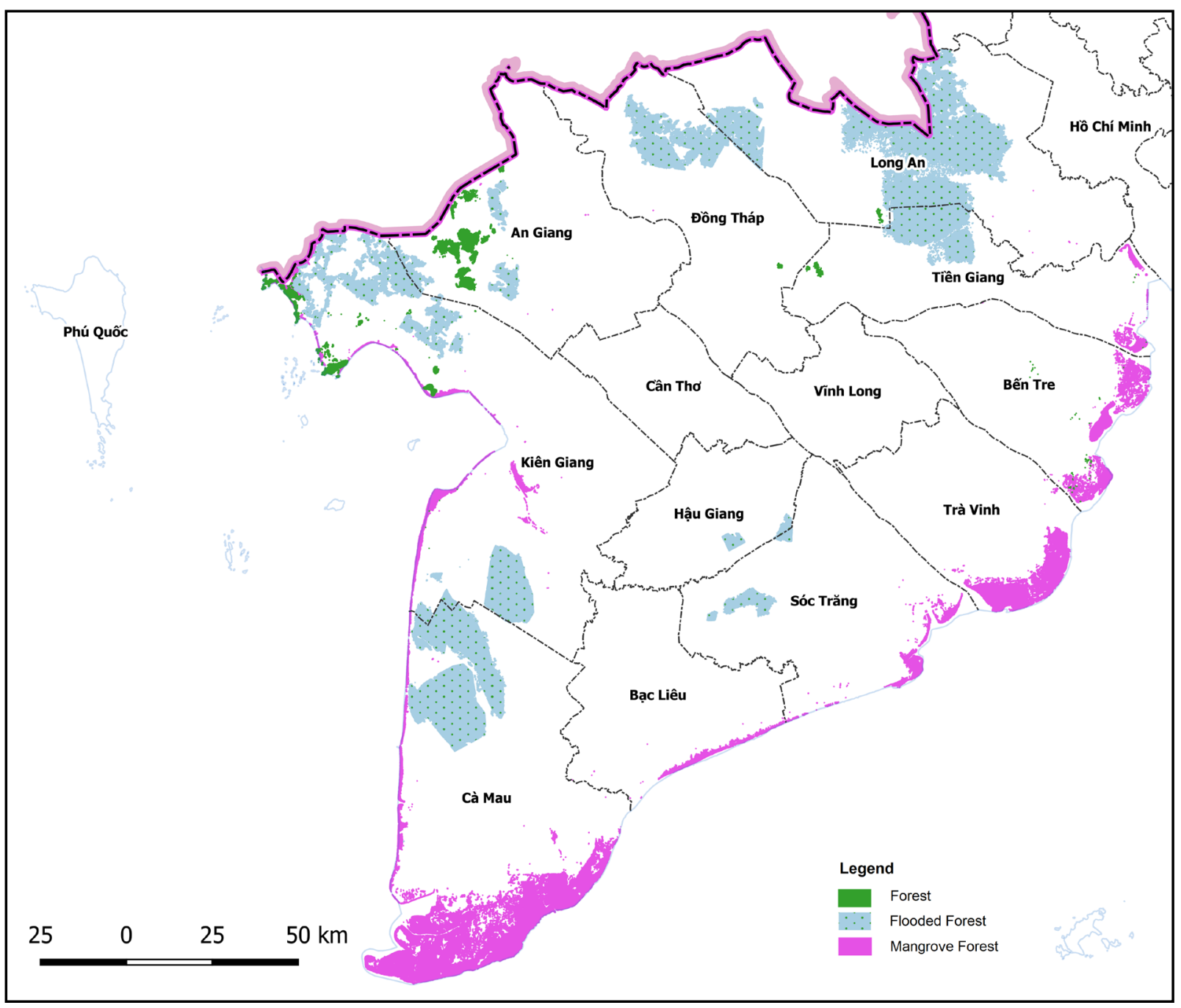

(a) 


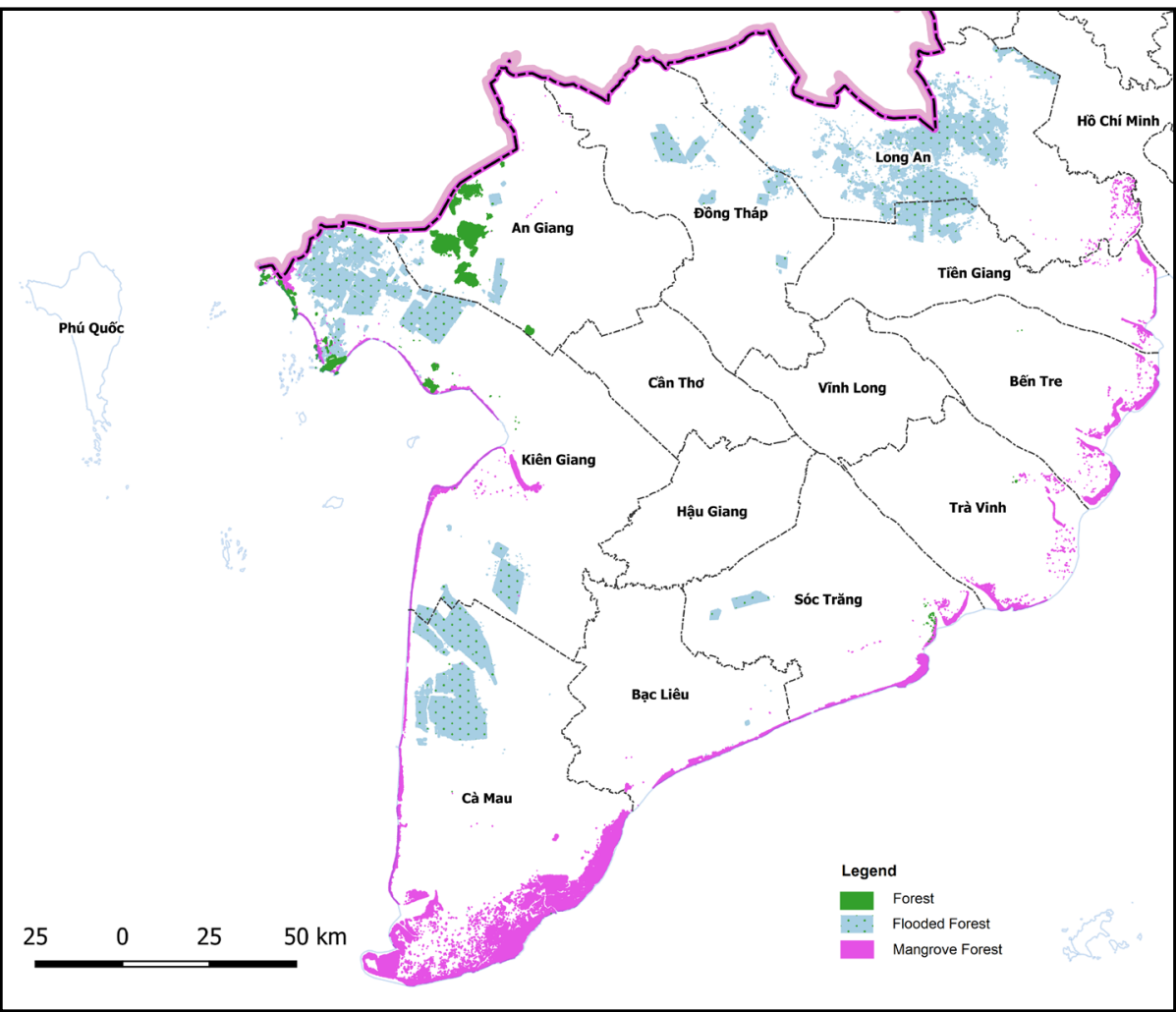

(b)

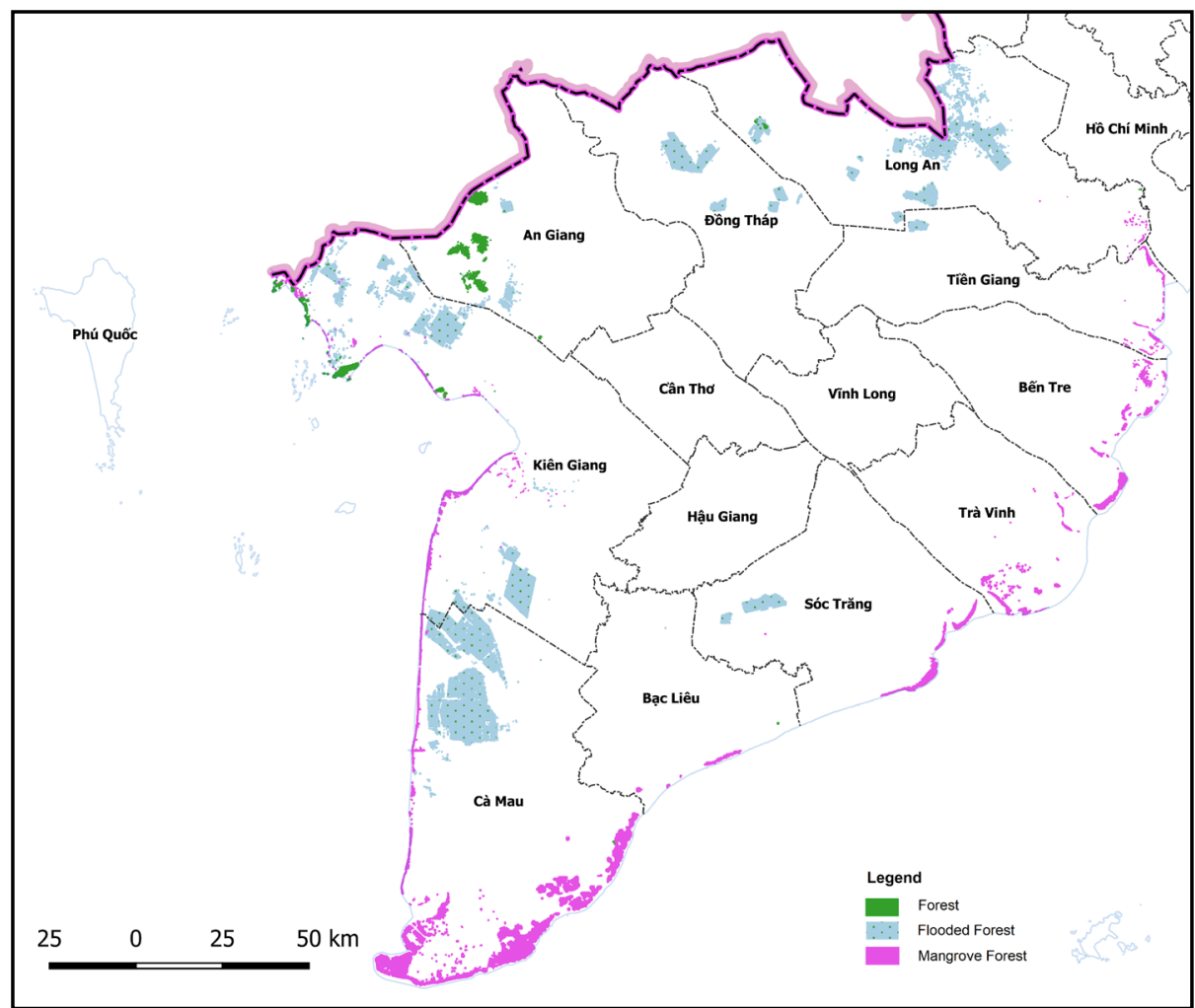

(c)

Figure 7. The forest-cover thematic data of Mekong Delta (a) in 1999; (b) in 2005; and (c) in 2015. 


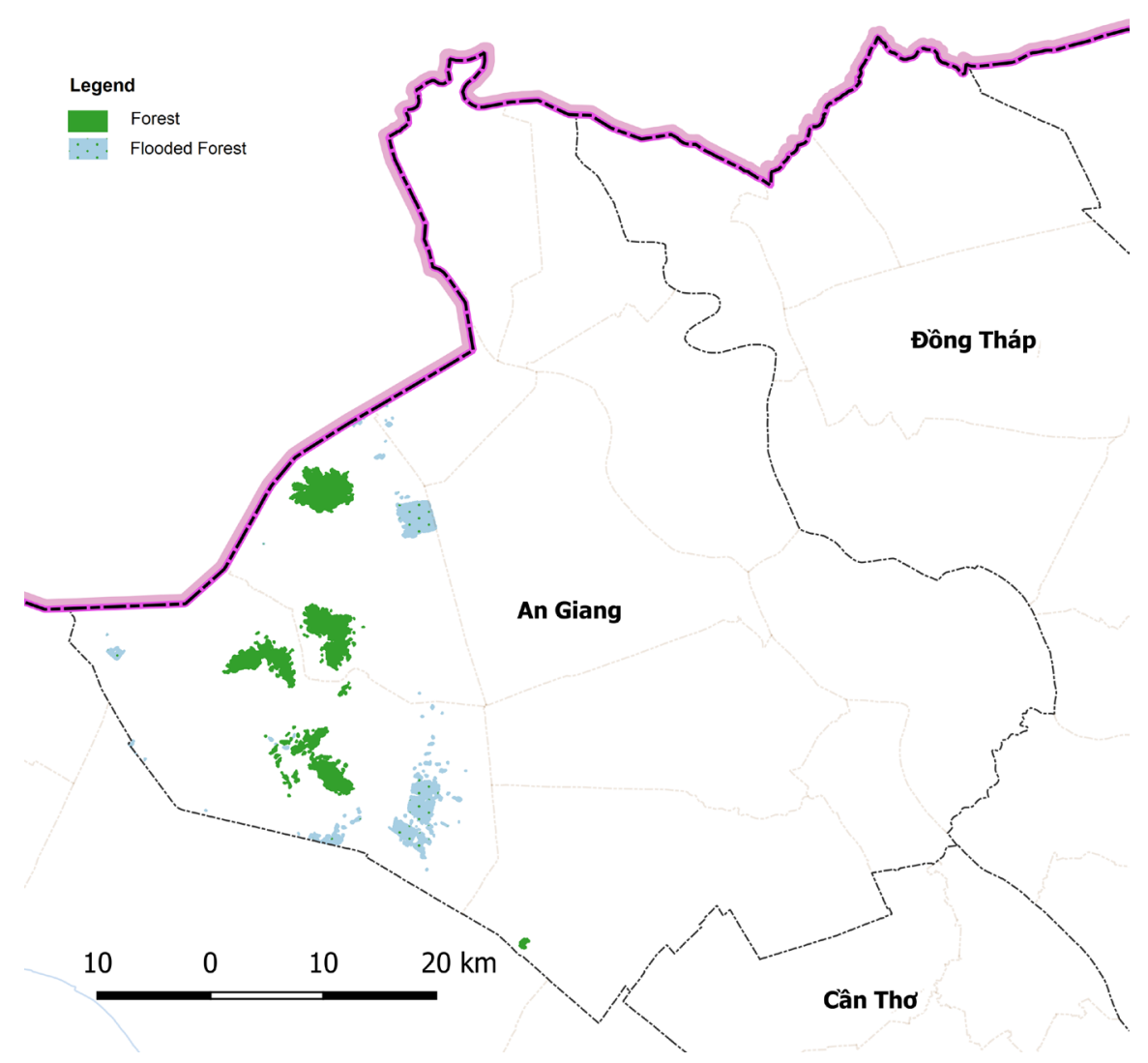

Figure 8. The forest-cover thematic data of An Giang province in 2015.

Web GIS solution for integrating and sharing data among administration agencies on the status and changes in forest-cover rate opens up a new way of developing GIS applications whereby the GIS server produces the thematic maps and then specialists of administration agencies can add some more information to it. This can assist the researchers and operational analysts to undertake further analysis regarding natural resources management that aims to achieve sustainable development in the Mekong Delta region.

\section{Conclusion}

MGIS plays the important role in sharing and integrating database among administration agencies with framework that can be used to build other applications that aims to achieve sustainable development in the Mekong Delta region. The proposed solution with standards of technology concerned with the actual development of the MGIS's applications that can apply efficiently for developing GIS of 12 provinces and a city in this region. Database of MGIS can be shared and presented within a web browser, without the need for any additional software, to provide information quickly for state management that ensures the efficiency of investment. This solution can bring more value on understanding the regional level situation and analyzing the trend of forest-cover change of each province. The development a web-based MGIS also contributes to create good 
opportunity for international organizations to undertake further analysis regarding land cover/land use change in this region.

\section{Acknowledgements}

This project has received funding from the Ministry of Science and Technology of Vietnam's Science and Technology for the sustainable development of Mekong Delta region program (KHCN-TNB/14-19), under grant agreement No. KHCN-TNB.ĐT/14-19/C03.

\section{Conflicts of Interest}

The authors declare no conflicts of interest regarding the publication of this paper.

\section{References}

[1] Adnan, M., Singleton, A. and Longley, P. (2010) Developing Efficient Web-Based GIS Applications. UCL Working Papers Series, 44, 0-15.

[2] Kurbanov, O. (2015) Appied GIS: Web GIS Serving Public Safety in Central Asia. International Journal of Geoinformatics, 11, 69-74.

[3] Ministry of Natural Resources and Environment (2016) Climate Change and Sea Level Rise Scenarios for Vietnam.

[4] Introduction to ASP.NET Core (2018). https://docs.microsoft.com/aspnet/core/

[5] GeoServer (2018). http://geoserver.org/

[6] PostgreSQL (2018). http://www.postgresql.org/

[7] Openlayers (2018). https://openlayers.org/ 